\title{
Processos Interacionais na Educação Musical: reflexões sobre a aula de instrumento musical
}

ANTONIO CHAGAS NETO

Antonio Chagas Neto é docente do Instituto Interdisciplinar de sociedade, Cultura e Artes IISCA da Universidade Federal do Cariri (UFCA). Doutor em Música - Educação Musical na Universidade Federal das Bahia (UFBA). Mestre em Música - Educação Musical - pela Universidade Federal da Bahia. Especialista em Ensino de Artes/Música pela Universidade Federal de Alagoas (UFAL). Licenciado em Música pela Universidade Federal de Sergipe. Atua na área de Educação Musical nas temáticas: Sociologia da Educação Musical, Interação, Ensino Particular de Música. (<http://lattes.cnpq.br/6641600397636689>).

AFILIAÇÃO: Universidade Federal do Cariri (UFCA), Juazeiro do Norte, Ceará 


\section{- RESUMO}

Este artigo busca apresentar reflexões sobre o processo de interação social durante uma aula de música. Para isso, será apresentado uma breve revisão de literatura tanto de conceitos sociológicos pertinentes ao tema quanto trabalhos na área da música que versam sobre esta temática. Em seguida, será apresentado trechos da análise de uma aula particular de violino, efetuados durante uma pesquisa de doutorado (NETO, 2018) que buscou compreender as interações sociais construídas durante uma aula de instrumento musical para crianças. Como fundamentação teórica, utilizou-se os conceitos de Goffman (2010; 2012; 2013). Por meio das análises, foi possível compreender que os comportamentos dos indivíduos agem e moldam a interação estabelecida, em um processo constante de retroalimentação.

\section{PALAVRAS-CHAVE}

Aula de instrumento musical; interações sociais; aula de música.

\section{ABSTRACT}

This article seeks to present reflections on the process of social interaction during a music lesson. For this, a brief review of the literature will be presented both on sociological concepts pertinent to the theme and works in the area of music that deal with this theme. Then, excerpts from the analysis of a private violin lesson will be presented during a doctorate research (NETO, 2018) that sought to understand the social interactions built during a musical instrument class for children. As theoretical foundation, the concepts of Goffman $(2010 ; 2012$; 2013) were used. Through the analyzes, it was possible to understand that the behaviors of the individuals act and shape the established interaction, in a constant process of feedback.

\section{KEYWORDS}

Musical instrument class; social interactions; Erving Goffman. 


\section{Introdução}

Ao pensarmos em uma aula de instrumento musical, rapidamente nos vem à mente uma enorme gama de variáveis, como a idade dos envolvidos, o instrumento musical escolhido, o local, o ambiente, a estrutura física, o material didático, a metodologia, e muitos outros a depender da especificada de cada situação. Essa enorme quantidade de fatores é palco para os mais diversos tipos de pesquisa científica com diferentes focos e objetivos.

Compreende-se que entre esses fatores, há uma atenção natural dos professores durante o planejamento da aula em relação aos métodos de estudo, a técnica instrumental que será abordada e o repertório que será utilizado, por exemplo. Essa atenção dada está principalmente atrelada à tentativa em alcançar os objetivos previamente estabelecidos.

Todavia, ao olhar esta situação com uma visão microssociológica, baseado principalmente no "cotidiano como algo revelador (PAIS, 1986, p.08) e as reflexões sobre o processo de interação social trazidas por Goffman (2010; 2012; 2013), pode-se compreender que a relação estabelecida entre os envolvidos se torna fundamental para a permanência ou não deste encontro social. Ou seja, que a intersubjetividade estabelecida durante a aula agirá durante o processo de ensino e aprendizagem.

Assim, este artigo busca refletir sobre a interação social que ocorre em uma aula de música e como esse fator pode agir no processo de ensino e aprendizagem. Para isso, inicialmente serão apresentados conceitos e trabalhos que versam sobre interação social e música, por meio uma breve revisão de literatura.

Em seguida, será apresentada uma parte da pesquisa de doutorado (NETO, 2018) que desenvolvi no Programa de Pós Graduação em Música da Universidade Federal da Bahia, entre os anos de 2014 e 2018, a qual tratou sobre as interações sociais construídas em uma aula particular de instrumento musical para crianças.

\section{Olhando o infinitamente pequeno}

Conforme exposto anteriormente, a interação é um conceito-chave, por isso é necessária uma compreensão mais aprofundada, visto que esta é uma palavra corriqueiramente utilizada em nossa sociedade. No ambiente escolar, não é raro ouvir de professores a frase "momento de interação entre os alunos", remetendo principalmente a situações onde há alguma ação coletiva educativa. Essa concepção pode nos fazer pensar que durante uma aula, há momentos em que a interação acontece, mas em outros, não. Será?

Para isso, é fundamental entender como a sociologia aborda este conceito e sua importância dentro da sociedade, não me utilizando assim apenas do uso do senso comum. É importante compreender como um aspecto tão subjetivo, ou meIhor, algo que trata da intersubjetividade dos indivíduos foi abordado por diferentes estudiosos.

Para Giddens e Sutton (2016), interação é "qualquer forma de encontro social, formal ou informal, entre dois ou mais indivíduos" (p. 232). Segundo eles, o interesse em estudar os encontros sociais iniciou a partir de 1920, através do 
interacionismo simbólico, dentro da Escola de Chicago. Buscavam dar um protagonismo para algo que parecia irrelevante, a partir dos estudos da rotina cotidiana e das relações entre os indivíduos, o que possibilitou a abertura de um caminho para compreender como é estruturada e formada a vida das pessoas. Segundo Hans Joas (1999), o nome dessa linha surgiu apenas em 1938 por Hebert Blumer, onde o enfoque.

são os processos de interação - ação social caracterizada por uma orientação imediatamente recíproca - , ao passo que o exame desses processos se baseia num conceito específico de interação que privilegia o caráter simbólico da ação social (JOAS, 1999 p. 130).

A busca por uma melhor compreensão sobre o processo de interação é uma temática utilizada por pesquisadores em diversos países. Contudo, dentre diversos autores que tratam da interação no sentido sociológico, Joseph (2000), Watson (2004), Bourdieu (2004), Velho (2008), Martins (2008), Frehse (2008) tratam como uma das principais referências o canadense Erving Goffman (2010; 2012; 2013),.

Isso se deve porque este autor se interessava, desde o início de sua carreira, com o que se passa quando há copresença de duas pessoas, sendo isso justamente o ponto central do meu objeto de estudo. Segundo Bourdieu (2004):

Goffman terá sido aquele que fez com que a sociologia considerasse o infinitamente pequeno: aquilo mesmo que os teóricos sem objeto e os observadores em conceitos não sabiam perceber e que permanecia ignorado, porque muito evidente, como muito evidente, como tudo que é óbvio. (BOURDIEU, 2004, p. 11).

O impacto das pesquisas dele foi tão grande para diversas áreas que atualmente há um arquivo virtual denominado Erving Goffman Archive, hospedado na Intercyberlibrary, criado pelos professores Sherri Cavan e Dmitri Shalim, da Universidade de Nevada - Las Vegas. O intercyberlibrary disponibiliza acesso à textos, reportagens, entrevistas, memoriais, biografias, críticas, pesquisas e documentos de diversos estudiosos que se debruçam sobre interação, além de trabalhos do próprio autor.

Segundo Scott (2009), "Goffman é um dos mais famosos proponentes da 'microssociologia', termo que ele cunhou para descrever seu interesse na interação social e seus efeitos sobre a identidade individual" (p. 129). Sua observação cuidadosa e prolongada de momentos de encontros entre as pessoas, trouxe novas reflexões e compreensões do comportamento humano.

Erving Goffman (1974, 2004, 2013). tem sido suporte teórico de diversas áreas de conhecimento. $\mathrm{Na}$ área de educação musical, ao efetuar um levantamento bibliográfico em anais de eventos científicos, revistas específicas, dissertações e teses, foram encontrados vinte trabalhos que o referenciaram. As temáticas destes trabalhos estavam atreladas ao contexto hospitalar; à portadores de necessidades especiais e ao processo de interação, relacionado respectivamente aos livros: Ma- 
nicômios, prisões e conventos (1974); Estigma (2004); e A representação do Eu na vida cotidiana (2013). Na temática sobre interação social e o comportamento das pessoas, além deste último livro citado, acrescento o Ritual de Interação (2012) e Comportamentos em Lugares Públicos (2010).

Esses estudos sobre a relação entre os indivíduos também se tornou uma curiosidade científica na área da música. Muitos pesquisadores começaram a se interessar em aspectos que vão além da análise do conteúdo musical, buscando uma melhor compreensão sobre os comportamentos dos indivíduos durante um encontro social que têm como principal foco a música, como aulas de música, apresentações musicais, prática coral, etc.

Como exemplo de pesquisa que trata sobre os processos de interação existentes em uma prática musical, destaco a tese de doutorado intitulada "Interações nos processos pedagógico-musicais da prática coral: dois estudos de caso" de Leila Dias que buscou "compreender as interações nas dinâmicas de ensino e aprendizagem em duas práticas corais, na cidade de Porto Alegre, RS, e como essas interações se reproduzem na vida dessas pessoas, dando origem a novas sociabilidades para além da prática coral." (DIAS, 2011, p. 05). Esta pesquisa analisa a relação face a face entre os indivíduos e sua influência, tanto em processos musicais como em extramusicais, auxiliando na compreensão de um aprendizado que transcende as aulas de música.

A pesquisa de Dias (2011) traz um olhar sobre o processo de interação entre indivíduos no meio musical, tendo como principal base teórica os trabalhos de Goffman (2012), além do aporte de Schütz (1974; 1984) para a prática musical coletiva e de Bauman $(2001 ; 2003 ; 2005 ; 2009)$ para uma melhor compreensão do sentimento de solidão proveniente da perda de alteridade. Assim, mesmo minha pesquisa não tratando de práticas musicais coletivas, os estudos da autora trazem contribuições relevantes sobretudo a respeito da microssociologia especificamente das interações sócio-musicais.

Simões e Álvares (2013) realizaram uma pesquisa quantitativa através de uma análise observacional sistemática da interação professor/aluno de três aulas coletivas de violão, tendo como referencial teórico Erbes (1972), utilizando-se o "Sistema de Observação de Interação de Ensaio" - RIOS. Neste trabalho, eram registrados cada comportamento em tempos padronizados, identificando momentos de início e término da interação que acontece entre os envolvidos a partir do diálogo. Entretanto, nos meus estudos utilizarei uma proposta diferenciada pois, ao utilizar como base o pensamento de Goffman (2010; 2012; 2013), emprego um conceito diferente de interação, o qual já inicia a partir da copresença de dois ou mais envolvidos, mesmo se nenhuma comunicação verbal se estabeleça. Com isso, a inexistência de interação em um ambiente compartilhado por indivíduos seria pouco considerada pelo autor.

Além destes, um dos primeiros trabalhos que buscou compreender a relação, ou mais especificamente, a interação entre professor e aluno na aula de música data do final da década de 1960, conforme indicam os estudos de Paul e Ballantine (2002) 
A obra de Rumbelow intitulada Música e Grupos Sociais: uma Abordagem Interacionista da Sociologia da Música (1969), foi a vanguarda deste movimento. Ele usou as teorias de interação simbólica de Mead para desenvolver conceitos do "gesto musical" como um fenômeno social e discutiu interações entre estudante-professor e o papel do músico na educação musical. (PAUL e BALLANTINE, 2002, p.570).

Na literatura internacional que trata das Interações na Educação Musical, destaca-se a pesquisa de Tore West e Anna-Lena Rostvall intitulada "Um estudo de interação e aprendizagem no ensino instrumental" (WEST e ROSTVALL, 2003). Nesta pesquisa, foram gravadas e analisadas onze aulas de violão e de instrumentos da família dos metais de quatro professores e 21 alunos, totalizando cinco horas de gravação e mais de quinhentas páginas de transcrição. Foi observado como professores e alunos usam seus discursos, sua linguagem corporal e a própria música durante o processo de ensino e aprendizagem.

Podemos notar que a relação entre professor e aluno perpassa a concepção simplória de pura transmissão de conhecimento. $O$ envolvimento ali presente proporciona uma relação intensamente afetiva. Mattos (2014) vem ao encontro de tal fato ao mostrar que o professor de música se apresenta, junto da profissão de professor, a função de "tutor de resiliência", ou seja, assume também outros papéis. Vale aqui ressaltar que tal peculiaridade pode ser percebida no ensino particular de música, principalmente quando as aulas ocorrem em domicílio, já que este profissional atua dentro da residência do aluno, estando envolvido, de forma direta ou indireta, no espaço de convivência familiar.

Ao tratar da temática "interação", muitos trabalhos de educação musical utilizaram conceitos e ideias defendidas por Goffman (2010), com destaque para o artigo intitulado "Audiência como ajuntamento social: interações na performance musical" de Fábio Henrique Ribeiro (2013). Neste artigo, os conceitos sobre os comportamentos em lugares públicos são utilizados para se compreender as interações ocorridas na performance musical de dois grupos de Congados no Estado de Minas Gerais. Ele também se utiliza de conceitos específicos como: ajuntamento social, reconhecimento cognitivo, reconhecimento social e engajamento social, o que possibilitou uma perspectiva mais aprofundada da performance. Nesta situação, Ribeiro (2013), destaca suas descobertas:

A possibilidade de compreender os processos de interação entre a sociedade e os grupos ampliou minha perspectiva a respeito das suas estruturas subjacentes e, consequentemente, da constituição da performance musical (RIBEIRO, 2013, p. 03).

Como as interações sociais permeiam nossa vida de maneira explícita, torna-se relevante olhar cientificamente para elas nas diversas situações e contextos, com vistas ao aprimoramento das posturas humanas e, aqui de modo especial, nas posturas pedagógico-musicais. 
Percebe-se assim a preocupação desses pesquisadores com os aspectos musicais pedagógicos e sociais que estão presentes na aula de música, que vão além da estética ou da pura transmissão de conhecimento musical. As novas sociabilidades criadas a partir das interações, conforme estudado por Dias (2011); a troca de informações entre professor e aluno por meio do discurso, da linguagem corporal e da própria música no processo de ensino e aprendizagem apresentadas por West e Rostvall (2003); os novos papéis assumidos pelos professores, conforme afirmado por Mattos (2014); e a mutualidade da interferência no comportamento intermediado pela interação, explicado por Ribeiro (2013) puderam trazer novas reflexões e fontes de informações para minha pesquisa.

Essas reflexões se baseiam na premissa de que a aula de música é um fenômeno muito mais complexo por não se apoiarem apenas nos conteúdos transmitidos mas, muito mais que isso, nas relações que são construídas, nas novas sociabilidades, nas trocas de saberes.

\section{Desvelando uma aula particular de música}

Nesta perspectiva, desenvolvi uma pesquisa de doutorado (NETO, 2018), onde busquei compreender as relações de ensino e aprendizagem que se constroem em uma aula particular de instrumento musical, a partir das interações que ocorrem entre os envolvidos. Neste trabalho, efetuei três estudos de caso, observando aulas particulares de violino e flauta doce para crianças. Neste artigo, irei apenas apresentar quatro situações analisadas durante uma das aulas de violino. É importante frisar que o objetivo da pesquisa não era analisar a conduta pedagógica do professor, mas compreender a relação interpessoal ali estabelecia.

A aula particular de violino observada ocorreu em Aracaju-SE, na sala de estar da residência da avó da aluna Clarinha, de 03 anos de idade. A coleta do material foi realizada pelo próprio professor, por meio de registro audiovisual. O conteúdo musical trabalhado foi a técnica instrumental, abordando notas no instrumento, postura e exercícios de corda solta.

Durante uma aula particular de instrumento musical, pressupõe-se que haja uma interação peculiar, fruto do processo de ensino e aprendizagem ocorrido naquele momento, intermediados pelos materiais didáticos utilizados; o ambiente domiciliar transformado em profissional; a intervenção de terceiros residentes naquele espaço; as expectativas trazidas pelos alunos em relação ao estudo musical, entre outros.

O primeiro aspecto a ser destacado é o fato de que o comportamento do professor agia diretamente no comportamento da aluna e vice-versa. Observe a imagem a seguir:

Nela, pode-se perceber que o professor mostra em suas mãos o arco do violino para aluna. Este movimento faz com que a aluno direcione seu olhar para o objeto que está nas mãos do professor, estabelecendo assim um envolvimento na situação. Se o professor, ao invés de mostrar o arco em suas mãos, apenas falasse sobre o objeto, não estimularia tal atitude da aluna. Isso se deve ao fato de que o processo de comunicação entre os indivíduos vai além de aspectos verbais, conforme afirma Goffman (2010) 


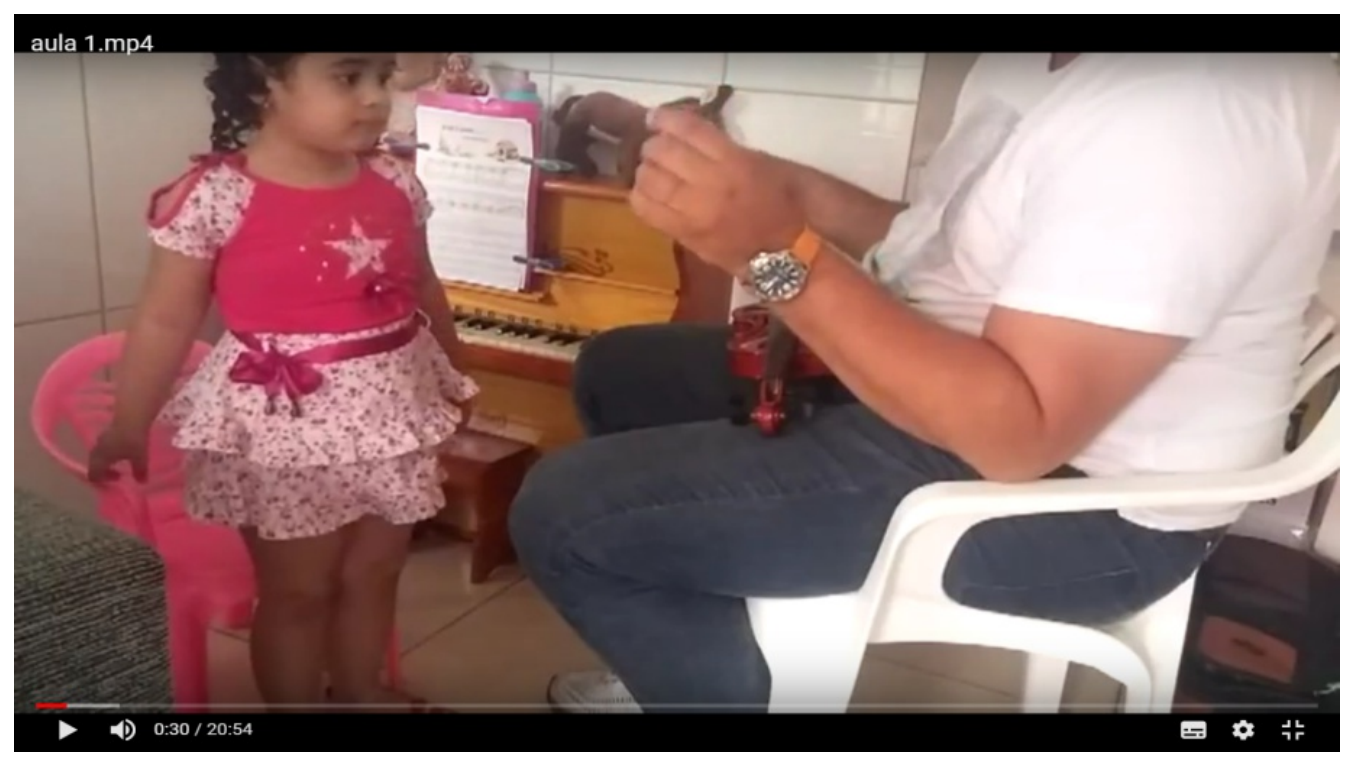

Figura 1- aluna observando arco na mão do professor. Imagem retirada do registro audiovisual efetuada por Marcone Matusalém (2017)

[...] quando indivíduos entram em presença imediata uns dos outros onde não é preciso nenhuma comunicação falada, eles ainda assim inevitavelmente iniciam uma espécie de comunicação, pois em todas as situações, atribui-se importância a certos assuntos que não estão necessariamente ligados às comunicações verbais particulares (GOFFMAN, 2010, p. 43)

Assim, a atitude gestual do professor é utilizada como uma estratégia pedagógica na aula, estimulando um "engajamento de face" (GOFFMAN, 2014, p. 101) por parte da aluna, causando um foco de atenção visual e cognitiva, intensificando a qualidade do envolvimento na situação.

Outro elemento utilizado pelo professor no momento desta imagem é a forma que fala com a aluna: "Olha, você lembra o nome desse, desse...". Ao não finalizar a frase, o professor deixava claro que aguardava uma resposta da aluna; que esperava uma ação dela. Conforme havia estabelecido uma qualidade de envolvimento na situação descrita anteriormente, a aluna continuou a participar, respondo ao questionamento.

O segundo momento que destaco é quando o professor entrega o arco à aluna, enquanto coloca a flanela no violino que se encontra ainda em seu colo. Neste episódio, Clarinha não espera o professor lhe entregar o violino, tendo mais uma atitude inesperada: tocar o instrumento com o arco ainda no colo do professor. Isso resultou na danificação da crina, conforme retratado no diálogo:

Aluna: Vou segurar aqui [apontando para a parte do talão do arco] dá para tocar assim o violino, o!... [a aluna tenta passar o arco nas cordas do violino ainda no colo do professor] 
Professor: Não, assim não Clarinha. Pode enganchar! [o professor percebe que a crina do arco já enroscou nos microafinadores] solta Clarinha.

Aluna: Aqui oh!...

Professor: Peraí Clarinha!

[A aluna solta o arco e volta sua atenção ao violino que ainda está no colo do professor, com a crina do arco presa nos microafinadores.]

Professor: Não pode fazer isso, olha só o que aconteceu. Só pode passar no lugar certo.

$\mathrm{O}$ arco do violino é formado pela haste, normalmente feita de uma madeira flexível como o pau-brasil e por um filamento de aproximadamente duzentos fios, que podem ser de crina de cavalo natural ou nylon. Ao apertar o parafuso localizado na região inferior, a haste é tensionada e consequentemente a crina também, formando uma espécie de fita. Caso haja uma perda considerável na quantidade de fios do arco, haverá falhas nestes filamentos, resultando em uma perda na qualidade do som produzido, necessitando sua substituição. É importante que o professor apresente para os alunos esses cuidados básicos, para que o instrumento não seja prejudicado.

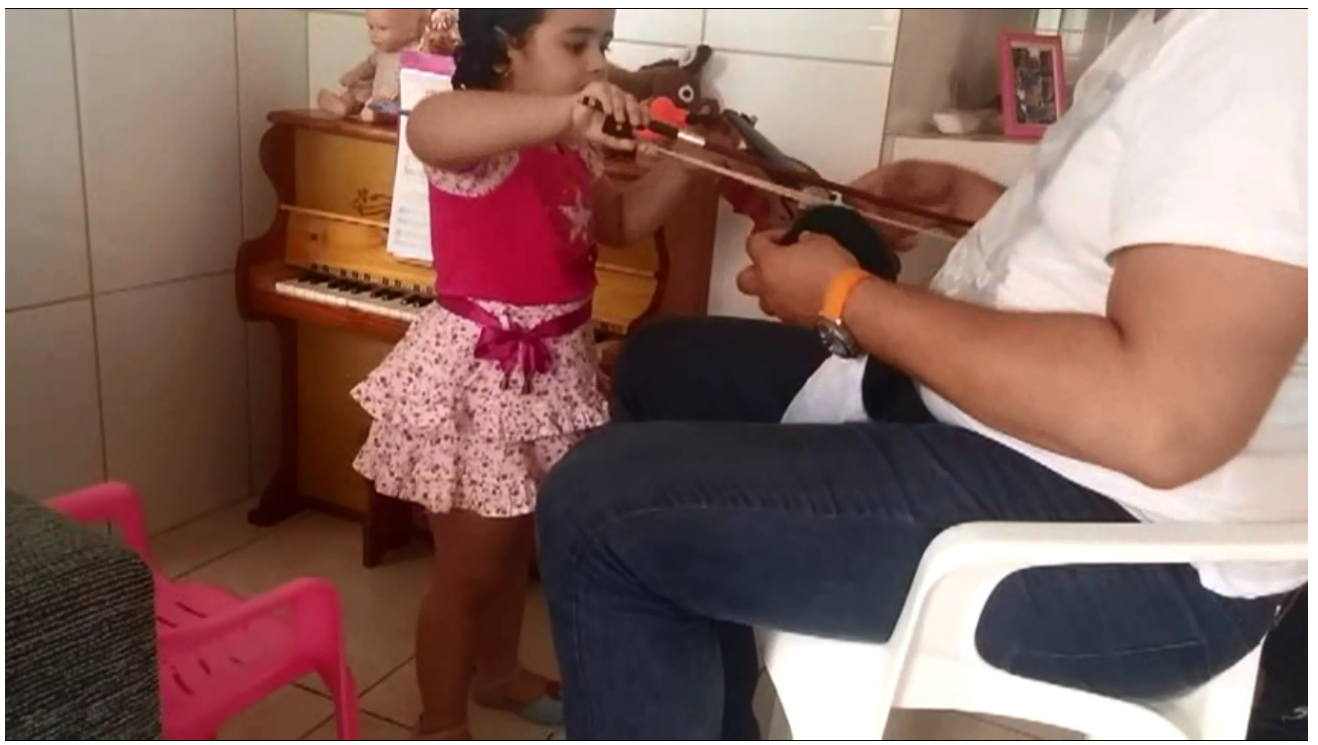

Figura 2 - crinas do arco presas nos microafinadores. Imagem retirada do registro audiovisual efetuada por Marcone Matusalém (2017)

Diante disso, o professor mostra as crinas danificadas que soltaram do arco, por estas terem se enroscado nos microafinadores. Esta foi a primeira vez que o professor repreendeu sua aluna e interrompeu a aula, repercutindo no modo como eles se relacionavam até então, pela seriedade com que o professor se expressou. Conforme retratado por GOFFMAN (2010), a interação estabelecida na situação social vai agir sobre os comportamentos de todos os envolvidos, que por meio de uma retroalimentação das ações estabelecidas, pode estimular a permanência ou 
modificação dessa situação. Com isso, cria-se "regulações que governam envolvimentos mantidos dentro de uma situação" (GOFFMAN, 2010, p. 214).

O terceiro momento destacado é quando perde-se a qualidade do envolvimento da aula na aula, após aproximadamente dez minutos de duração. A seguir, descrevo o diálogo estabelecido entre o professor e a aluna.

Professor: Olha, presta atenção! Que notinha é essa aqui?

Aluna: Dó [responde tentando sentar em um objeto que se encontrava fora do ângulo da câmera]

Professor: Não...

Aluna: Mi

Professor: O titio acabou de falar! Lá, a notinha lá de lápis. Sentadinha!!! [a aluna ainda está tentando subir em uma caixa de madeira alta. O professor a auxilia para descer] Assim não Clarinha, para não cair [A aluna desce com um sorriso no rosto]. A notinha lá e a notinha ré [Ela volta a tentar subir na caixa ao lado]. A gente vai tentar tocar somente essas duas notinhas, tá bom? Já descansou? [Neste momento, ela desce e caminha para outra direção] Clarinha! Não pode sair!

O diálogo acima apresenta muitos elementos importantes para se refletir sobre as relações entre professor e aluno nesse processo de ensino e aprendizagem. Nas três primeiras linhas, o professor pergunta para aluna o nome da segunda corda do violino. Como ela está tentando subir em uma caixa, não presta atenção à pergunta e se confunde ao responder o nome da nota.

Em um diálogo em que os indivíduos não estejam focados e envolvidos no mesmo assunto, podem se confundir nas respostas, sem um comprometimento com a exatidão e a satisfação do outro. Uma resposta dada apenas por conveniência, como cumprimento de uma solicitação, sem necessariamente atendê-la devidamente. Para Goffman (2012, p. 114-115), "o envolvimento conjunto parece ser uma coisa frágil, com pontos-padrão de fraqueza e decadência", tendo assim variações na sua estabilidade. Essa instabilidade pode ser causada por uma preocupação externa ao fato em comum do diálogo, conforme visto no último diálogo entre o professor e a aluna.

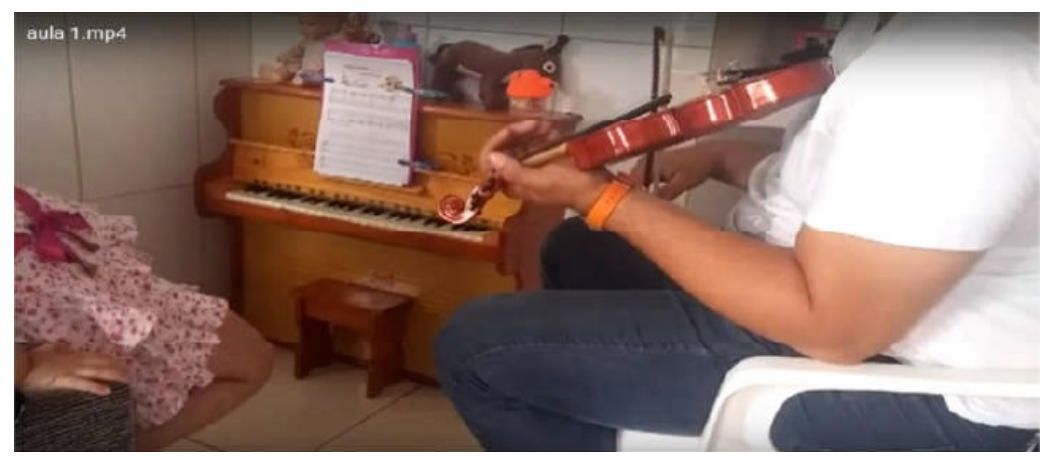

Figura 3 - aluna afastada do professor. Imagem retirada do registro audiovisual efetuada por Marcone Matusalém (2017) 
O quarto momento destacado é o diálogo estabelecido entre professor e a aluna, durante o final da aula, no momento de guardar o instrumento, conforme apresentado abaixo

Aluna: E vou, eu posso botar sozinha...

Professor: Deixa eu falar...ói Clarinha, não pode segurar aqui ó [apontando para a crina do arco]

Aluna: É só aqui [apontando para vara]

Professor: Pega aqui embaixo [ a aluna puxa o arco] Calma Clarinha!

Escuta só

Aluna: Ah.., mas eu, mas eu...vou guardar

Professor: Eu sei que você vai guardar, mas o tio [nesse momento a aluna solta o arco] só vai te explicar como vai guardar, ói. O arco folga [o professor movimenta o parafuso no final do arco] Tem que folgar o botãozinho. Quando for tocar, aperta. Quando for guardar, a gente folga. O titio vai mostrar uma vez como guardar, depois você guarda, tá bom? Olha só, preste atenção [a aluna fica observando atentamente] Essa parte... [ o professor coloca a ponta do arco dentro do estojo, mas antes disso, a aluna fala]

Aluna: Eu.... [a aluna tenta pegar o arco novamente]

Professor:: Clarinha, escuta só Clarinha, o titio vai te ensinar e depois você guarda, tá bom? Ói, coloca essa parte [nesse momento, a aluna pega novamente o arco]

Aluna: É eu...eu guardo assim

Professor: Não, Clarinha. Olha a crina. Olha, o titio vai guardar.

Aluna: Me empresta, me empresta [a aluna estica a mão para tentar pegar o arco que está na mão do professor]

Professor: Eu vou deixar você guardar

Aluna: Por que você não me empresta para eu poder abaixar assim na caminha dele para ele dormir?

Nesse diálogo, o professor tenta ensinar à aluna a maneira mais indicada para se guardar o arco, para assim, evitar qualquer danificação. Contudo, o professor tem alguns problemas causados pelo envolvimento exagerado dela na situação, o que interfere diretamente no comportamento de ambos, dificultando a continuidade da explicação. Para Goffman (2012), quando um indivíduo se envolve exageradamente no tópico da conversação pode dar a impressão de que "não tem um grau necessário de autocontrole sobre seus sentimentos e ações" (GOFFMAN, 2012, p. 119), os quais são fundamentais para o convívio em um ambiente coletivo.

Quando a aluna insiste em pegar o arco da mão do professor, ela quer satisfazer uma vontade própria, independentemente das consequências e/ou dos participantes da mesma situação. Sobre isso, Goffman observa que a disposição de envolver-se exageradamente é uma forma de "tirania" exercida por crianças, que "momentaneamente colocam seus próprios sentimentos sobre as regras morais que deveriam tornar a sociedade segura para a interação" (IBDEM). 


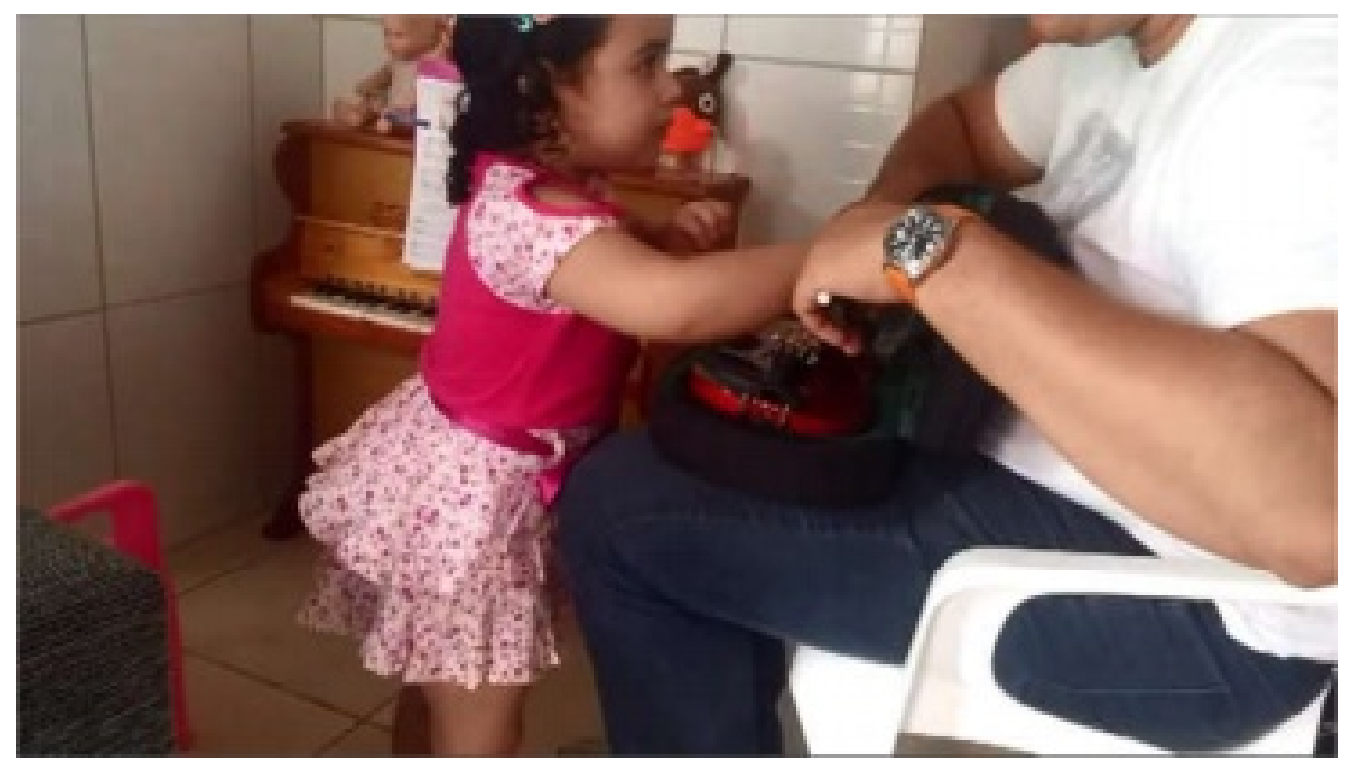

Figura 4- aluna tentando pegar o arco enquanto o professor tenta guarda-lo. Imagem retirada do registro audiovisual efetuada por Marcone Matusalém (2017)

Nas falas do professor, percebe-se seu desconforto pelo comportamento insistente de Clarinha e, em contrapartida, sua reação é de não atender, de imediato, o pedido dela, gerando também uma situação desconfortável para sua aluna. Esse pode ser um exemplo de mutualidade da interação imediata, onde os comportamentos socialmente esperados por um indivíduo durante um encontro não são atendidos.

\section{Considerações finais}

Esta pesquisa realizada no campo da Educação Musical faz uma visita a algumas questões sociais em um olhar microssociológico. Nela, buscou-se compreender as relações de ensino e aprendizagem que se constroem em uma aula particular de instrumento musical, a partir das interações que ocorrem entre os envolvidos.

Estas interações abordadas aqui se referem ao comportamento de um indivíduo que age sobre o outro em um fluxo de retroalimentação. São conceitos bebidos da fonte dos estudos de Erving Goffman (2010; 2012; 2013) que acredita na mutualidade da interação imediata.

Durante a pesquisa, pôde-se compreender que não há comportamentos isolados. O somatório entre o contexto, as experiências prévias e a relação com o outro constroem "comportamentos situacionais", conforme esse mesmo autor. Ou seja, podem ser comportamentos distintos a depender do momento, mas apresentam relações interdependentes, sendo caracterizado por constantes adaptações.

Diante disso, é necessário que os educadores musicais se sensibilizem para a peculiaridade desse contexto que é imbricado de liberdades e repreensões, assim como de relações humanas com diferentes papéis a serem desempenhados. Tudo 
isso precisa ser visto por nós, desde o momento de planejamento da aula, perpassando pelos processos do desenvolvimento de cada atividade realizada, sem deixar de avaliar o que deu certo e o que não deu em cada uma delas, para que possa ser feito um novo planejamento com empatia.

Sabemos que tudo isso interfere no estímulo de nossos alunos para continuarem ou desistirem de aprender um instrumento musical. Às vezes, não se descobre o que eles querem aprender, quais são seus gostos musicais, se as aulas foram contempladas com um repertório interessante. Também há que se resignificar aquelas aulas em que o foco central se volta apenas para as questões técnicas de execução instrumental, esquecendo de promover momentos de experiências musicais.

Além disso, há que se pensar no real significado das relações humanas tão presentes nos depoimentos trazidos neste estudo. O Ensino Particular de instrumento exige de nós um pensar que possa olhar para as subjetividades de cada novo aluno, de cada faixa etária, de cada ambiente familiar e no seu modo de socializar. Este contexto passa a ser um espaço, não só de aula de instrumento, mas também de afetos e conveniências. Assim, a adaptação torna-se uma preocupação necessária para dar significado aos objetivos daquela ação educativa, naquele espaço microssocial, já que cada ação vai gerar uma nova reação, dinâmica da interação.

\section{REFERÊNCIAS}

BOURDIEU, Pierre. Goffman, o descobridor do infinitamente pequeno. IN: GASTALDO, Édison. Erving Goffman: desbravador do cotidiano. Porto Alegre. Tomo Editorial, 2004. p. 11-12.

NETO, Antonio Chagas. INTERAÇÕES SOCIAIS CONSTRUÍDAS NO ENSINO PARTICULAR DE VIOLINO E FLAUTA DOCE: estudos de caso sobre relações de ensino e aprendizagem com crianças de dois e três anos. 163 f. il. 2018. Tese de Doutorado - Escola de Música, Universidade Federal da Bahia, Salvador, 2018

DIAS, Leila Miralva Martins. Interações nos processos pedagógico-musicais da prática coral: dois estudos de caso. Tese de Doutorado. Porto Alegre. PPGMUS/UFRGS. 2011.

FREHSE, Fraya. Erving Goffman, sociólogo do espaço. Revista da RBCS. V. 23. 2008. p. 154-200.

GIDDENS, Anthony; SUTTON, Philip W. Conceitos essenciais da sociologia. Tradução de Claudia Freire. São Paulo. Editora UNESP. 2016.

GOFFMAN, Erving. Manicômios, prisões e conventos. Tradução de Dante Moreira. São Paulo. Perspectiva. 1974.

Estigma - notas sobre a manipulação da identidade deteriorada. Publicação original: 1988. Digitalização: 2004.

Comportamentos em Lugares Públicos: notas sobre a organização social dos ajunta- 
mentos. Tradução de Fábio Rodrigues Ribeiro da Silva. Petrópolis-RJ. Vozes. 2010.

Ritual de Interação: ensaios sobre o comportamento face a face. Traduzido por Fábio Rodrigues Ribeiro da Silva. Petrópolis-RJ. Vozes. 2012.

A representação do eu na vida cotidiana. Traduzido por Maria Célia Santos Raposo.

Petrópolis-RJ. Vozes. 2013.

JOAS, Hans. Interacionismo Simbólico. In: GIDDENS, Anthony; TURNER, Jonathan. Teoria Social Hoje. Gilson César Cardoso (Trad.). São Paulo: Editora UNESP. 1999. p. 127-174.

JOSEPH, Isaac. Erving Goffman e a microssociologia. Tradução: Cibele Saliba Rizek. Rio de Janeiro. Editora FGV. 2000.

MARTINS, Carlos B. de C. Dossiê Goffman - Apresentação. Revista RBCS. V. 23. 2008. p. 135-136.

MATTOS, Sandra Carvalho. O professor de música como tutor de resiliência. Anais do XXIV Congresso da Associação Nacional de Pesquisa e Pós-Graduação em Música. São Paulo. 2014.

PAIS, Jose Machado. Paradigmas sociológicos na análise da vida cotidiana. Análise social. Vol XXII (90), 1986-1, p. 07-57.

PAUL, Stephen; BALLANTINE, Jeanne.The sociology of education and connections to music education research. IN: COLWELL, Richard; RICHARDSON, Carol. The new handbook of research on music teaching and learning.Oxford. Oxford University

Press. 2002. p. 566-584.

RIBEIRO, Fabio H. Audiência como ajuntamento social: interfaces na performance musical. Anais do XXIII Congresso da ANPPOM. Natal. 2013.

SCOTT, Susie. Erving Goffman. IN: SCOTT, John. 50 grandes sociólogos contemporâneos.Tradução: Renato Marques de Oliveira. São Paulo. Contexto. 2009. P. 129-134.

SIMÕES, Alan Caldas; ALVARES, Sérgio L. de Almeida. A descrição da interação professor-aluno em selecionadas aulas coletivas de violão: Uma análise observacional a partir do sistema RIOS. Anais do XXIII Congresso da Associação Nacional de Pesquisa e Pós-Graduação em Música. Natal. 2013.

WATSON, Rod. Lendo Goffman Em Interação. IN: GASTALDO, Édison. Erving Goffman: desbravador do cotidiano. Porto Alegre. Tomo Editorial, 2004. p. 81-100.

WEST, Tore, ROSTVALL, Anna-Lena. A study of interaction and learning in instrumental teaching.International Journal of Music Education.May. 2003.

Recebido em 24/02/2019 - Aprovado em 13/03/2019 
Como citar:

Neto, A, C. (2019) Processos Interacionais na Educação Musical: reflexões sobre a aula de instrumento musical. OuvirOUver, 15(1), 44-58. https://doi.org/10.14393/OUV24-v15n1a2019-3

(c) (7) \& $\begin{aligned} & \text { A revista ouvirOUver está licenciada com uma Licença Creative } \\ & \text { Commons Atribuição-NãoComercial } 4.0 \text { Internacional. }\end{aligned}$ 